\title{
Effect Of Fractionated And Single Doses Gamma Irradiation On Certain Mammalian Organs
}

\author{
Nabila A. R. Abdel Motaal* and Azza Abdel Maguid** \\ *Radiation Biology and ** Radiation Health Research Departments, National Centre \\ for Radiation Research and Technology, Cairo, Egypt.
}

\begin{abstract}
The present work aims to study the effect of fractionated and single dose whole body gamma irradiation on the liver, spleen and intestine of albino rats.

30 Male albino rats $(100-120 \mathrm{~g})$ were used as experimental animals, they were divided into three groups: The first group consists of 10 rats served as control group (non irradiated), the second group (10 rats) were subjected to a single dose of irradiation (5Gy) and the third group (10 rats) were subjected to gamma of irradiation (5Gy) delivered at 5 successive exposures daily.

Histological results showed serious histopathological disorders in the liver, spleen and intestine after exposure to the single dose of gamma irradiation (5Gy), manifested by inflammation and infiltration with mononuclear cells, haemorrhage, dilatation, congestion and widening of blood vessels and necrosis of cells with pyknotic nuclei.

Exposure of rats to fractionated doses of whole body gamma irradiation (1Gy) up to $5 \mathrm{~Gy}$ resulted in less severe histopathological disorders in liver, spleen and small intestine (jejunum),

This indicates the beneficial use of fractionated doses in planning for radiotherapy in cancer patients, thus reducing the serious histopathological changes of radiation on the human tissues.
\end{abstract}

\section{Introduction}

Life on earth has evolved in the presence of ionizing radiation from several sources. In addition to natural background radiation, humans are exposed from man made sources. The largest component of man-made background radiation relates to exposures associated with medical diagnosis and treatment (Kissan and Anderson 1985).

Exposure to radiation causes injury to blood vessels provoking anoxia of tissues with degeneration and necrosis (Jirtle et al., 1990)

Many of the damaging effects of ionizing radiations are mediated by free radicals. Superoxide (O) and hydroxyl radical $(\mathrm{OH})$ attack the polyunsaturated fatty acids of cell membrane phospholipids resulting in severe damage to cellular membrane organelles and their associated enzymes (Halliwell and Gutteridge, 1989). The cell membrane permeability is disturbed following irradiation as exhibited by changes in tissue ionic contents of $\mathrm{Na}$ and K (Hassan and Osman, 1996)

The biological effect of radiation correlates with the given doses (Fowler, 1994). The most important target in living cells is DNA. Ionizing radiation may directly damage DNA (direct target theory), but more often it indirectly damages DNA by inducing the formation of free radicals, particularly those that form the radiolysis of water (indirect target theory). Other cell molecules that may also be direct or indirect targets of radiant injury include lipids in cell membranes and proteins that function as critical enzymes. The transfer of energy to a target atom or molecules from the incident source of radiant energy occurs within micro fractions of a second, yet its biological effect may become apparent for minutes or, if the effect is on DNA, even decades (Kumar et al., 2003).

The objective of this work was to evaluate the ameliorative effect of the single or fractionated irradiation doses when planning a radiotherapy programme for medical practice aiming to reduce the 
possible radiation injury induced in cancer patients subjected to treatment by radiotherapy.

\section{Material and methods}

30 adult male albino rats (100$120 \mathrm{gm})$ were divided into three equal groups and were provided with standard diet and water.

Group I: Normal rats, used as control.

Group II: Irradiated animals subjected to a single irradiation exposure (5Gy) and sacrificed one day post-irradiation.

Group III: Irradiated animals subjected to irradiation (5Gy) delivered at 5 successive exposures daily then sacrificed 6 days post-irradiation.

Irradiation was carried out using Cs137 source (Gamma cell-40) belonging to Egypt's National Center for Radiation Research \& Technology (NCRRT) Cairo, Egypt.

10 rats were sacrificed from each group and rapidly dissected. The liver, spleen and intestine were removed for the histological procedure. Fixation was done in $10 \%$ formaline. Tissues were then dehydrated by passing in ascending grades of alcohol, and then the samples were cleared in xylol, followed by embedding in paraffin wax (soft then hard). Samples were serially sectioned at thickness of 5-6u.

The sections were then stained using haematoxylin \& eosin. Histological examinations were taken through light microscopy and photomicrographs were made.

\section{Results}

\section{Liver:}

Histological examination of liver sections from control, non irradiated rats revealed the normal histological structure of hepatic tissue (Fig.1).

Liver of rats exposed to the single dose of gamma irradiation (5Gy) showed marked dilatation and congestion of hepatic portal vein with detached endothelial lining. Most of the hepatocytes appeared vacuolated. Some nuclei appeared pyknotic and remnants showed karyolysis (Fig.2). Some examined cases revealed portal haemorrhages, monon-uclear cells infiltration and irregular ruptured endothelial lining of hepatic portal vein with highly affected wall. Most nuclei of hepatocytes were affected: Some of them were irregular others were atrophied while some of them appeared surrounded by large clear area. Disturbed bile canaliculi were also observed (Fig. 3) as well as small haemorrhagic areas with mononuclear cells infiltration around hepatic portal vein and large degenerated area with ballooning shape of hepatocytes were observed (Fig.4). Massive hepatic haemorrhage, hepatic necrosis associated with pyknotic nuclei, numerous vacuolated areas and hypertrophied hepatocytes obstructing the sinusoidal spaces inbetween were observed in the examined sections (Fig.5).

However, liver of rats exposed to accumulated, fractionated dose of gamma irradiation showed preservation of hepatic architecture with Kupffer cell activation and mild hydropic degeneration of hepatocytes. Cortical hepatocytes appeared affected than central ones (Fig.6).

Spleen:

Histological examination of spleen sections from control, non-irradiated rats revealed the normal histological structure of spleen from white pulp and red pulp. The white pulp consists of lymphoid follicles, while the red pulp consists of blood sinusoids (Fig.7). On the other hand, microscopical examination of spleen sections from rats exposed to the single dose of gamma irradiation showed marked dilatation and congestion of splenic blood vessels with prominent internal haemorrhage (Fig.8). Lymphocytic necrosis and dilatation as well as massive splenic haemorrhage and ill defined pulps were seen. Since large areas were destructed, the spleen lost its normal architecture (Fig.9) accompanied with deposition of golden brown haemosidrin pigments.

Histological sections from rats exposed to the fractionated doses of gamma irradiation revealed congestion of splenic blood vessels and mild lymphocytic necrosis of some lymphoid follicles with enlarged white pulp (Fig.10).

\section{Intestine:}

Examined sections from control, non-irradiated rats revealed the normal histological structure of small intestine 
illustrated in well developed intestinal villi, musculosa and serosa layers (Fig.11).

In contrast, sections of intestine of rats exposed to the single dose of gamma irradiation showed focal denuation and exfoliation of intestinal villus epithelium, activation of mucous secreting intestinal glands as well as mononuclear infiltration in the lamina propria, the villi appeared short and thick with ruptured columnar cells (Figs.12 and 13). Nearly all villi contained the debris of their cytoplasm and nuclei.

Examined sections from rats exposed to the fractionated dose of gamma irradiation showed only moderate activation of mucous secreting intestinal glands with enlarged villi and few of them were ruptured (Fig.14).

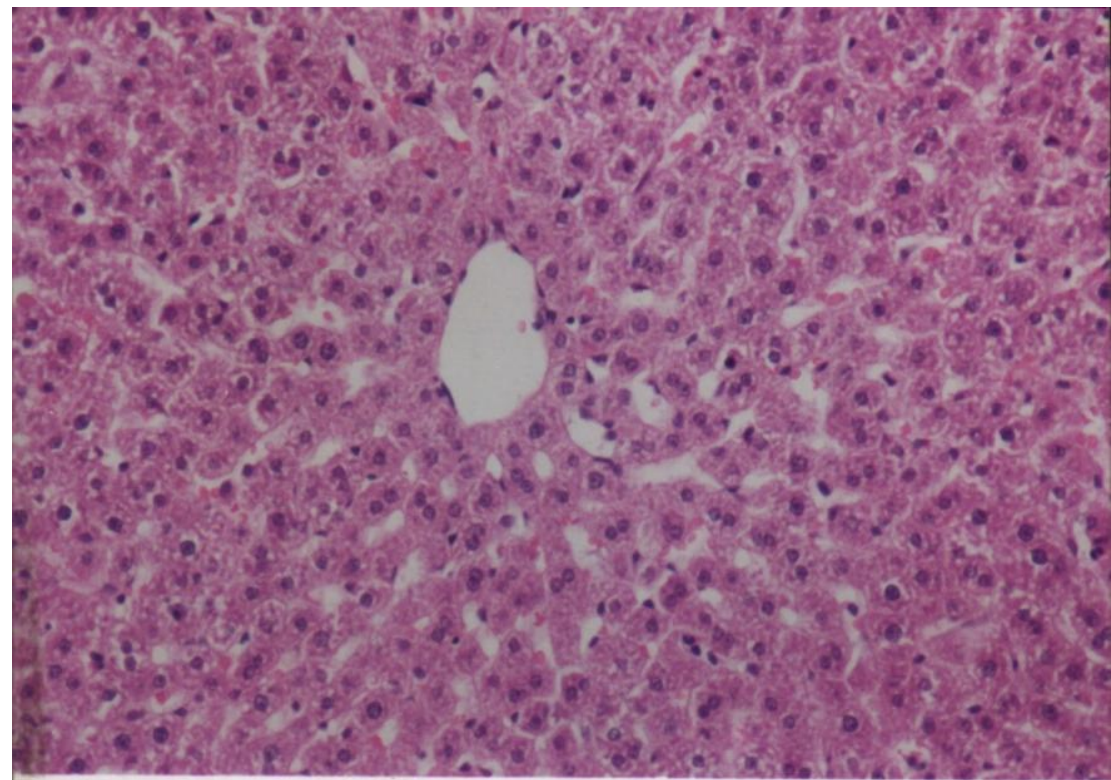

Fig.1:- Liver of control, non treated rat showing normal histological structure of hepatic lobule. (Hx and E X 200)

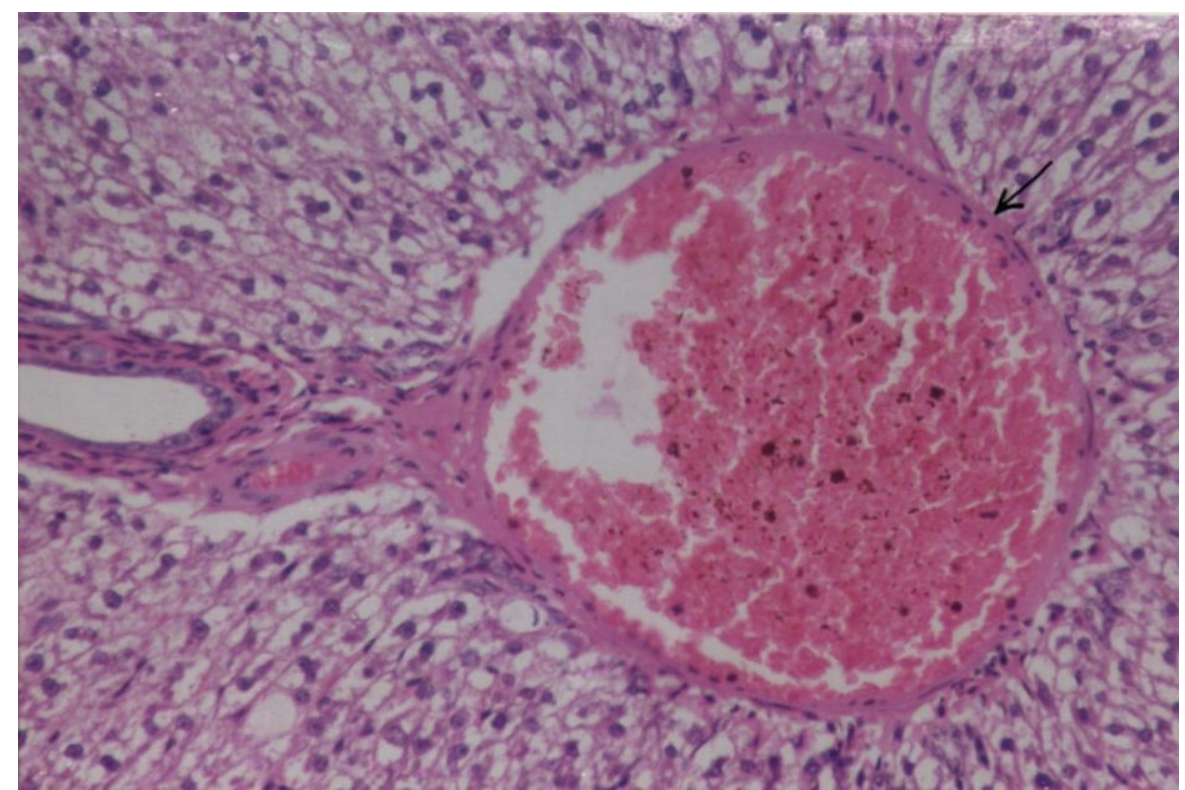

Fig.2:- Liver of a rat exposed to the single dose of gamma irradiation (5Gy) showing marked dilatation and congestion of hepatic portal vein (arrow) with detached endothelial lining (arrow head). Most hepatocytes appeared vacuolated (v). Some nuclei appeared pyknotic (p), remnants showed karyolysis (k). (Hx and E X 200). 


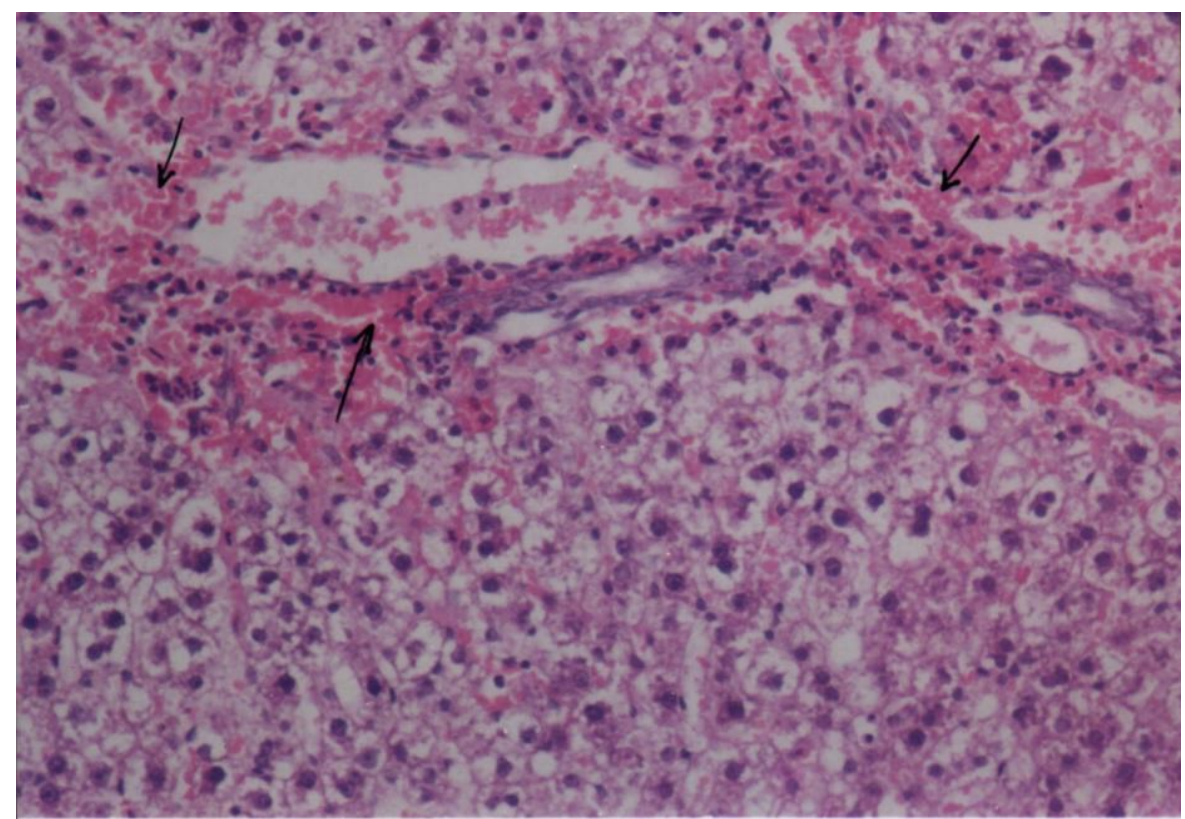

Fig.3:- Liver of a rat exposed to the single dose of gamma irradiation (5Gy) showing mononuclear cells infiltration and irregular \& ruptured endothelial lining of hepatic portal vein with highly affected wall (arrows). Most nuclei of hepatocytes are affected: Some are irregular (1) others are atrophied (2) while some of them appeared surrounded by large clear area (3). Disturbed bile canaliculi could also be observed (b.c). (Hx and E X 200).

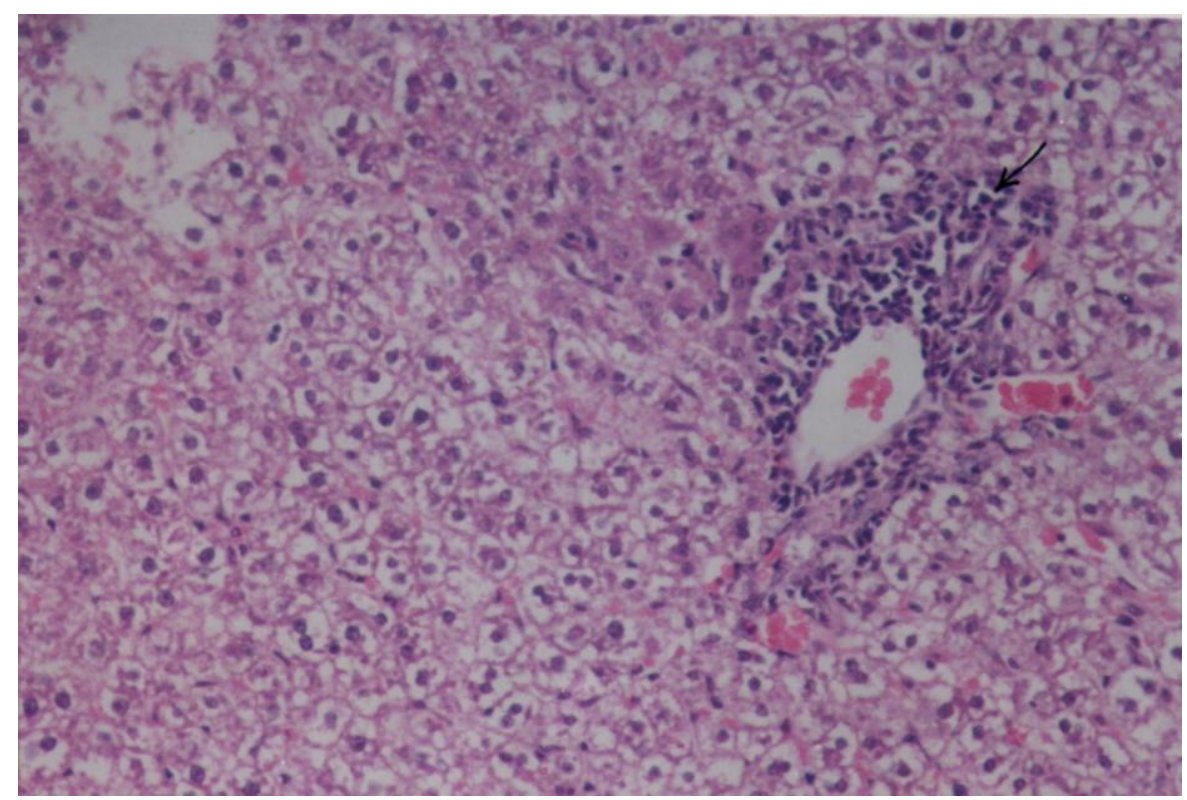

Fig.4:- Liver of a rat exposed to the single dose of gamma irradiation (5Gy) showing small haemorrhagic areas with mononuclear cells infiltration around hepatic portal vein (arrow). Large degenerated area was observed (d) with ballooning shape of hepatocytes. (Hx and E X 200). 


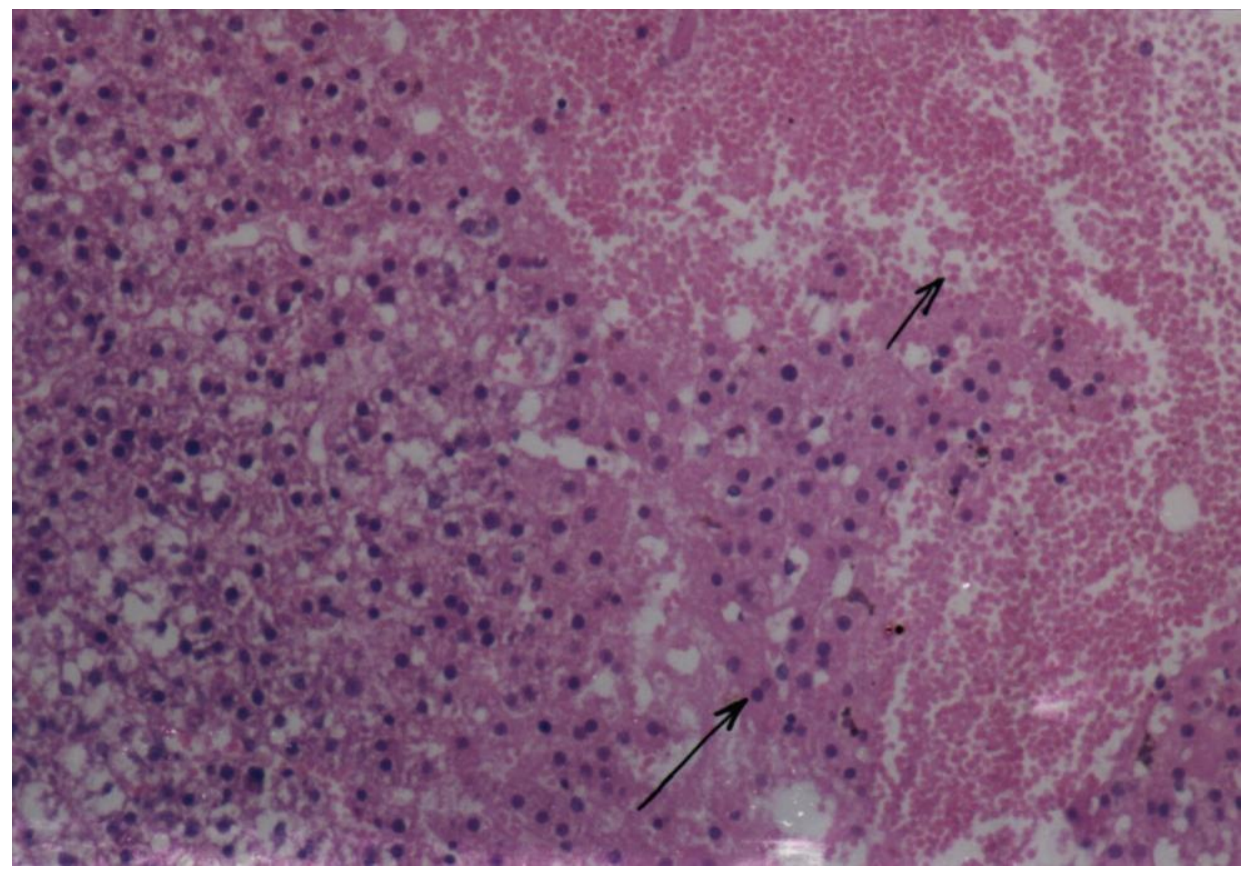

Fig.5:- Liver of a rat exposed to the single dose of gamma irradiation (5Gy) showing massive hepatic haemorrhage (small arrow), hepatic necrosis associated with pyknotic nuclei (large arrow). Numerous vacuolated areas (v). Hypertrophied hepatocytes obstruct the sinusoidal spaces inbetween. (Hx and E X 200).

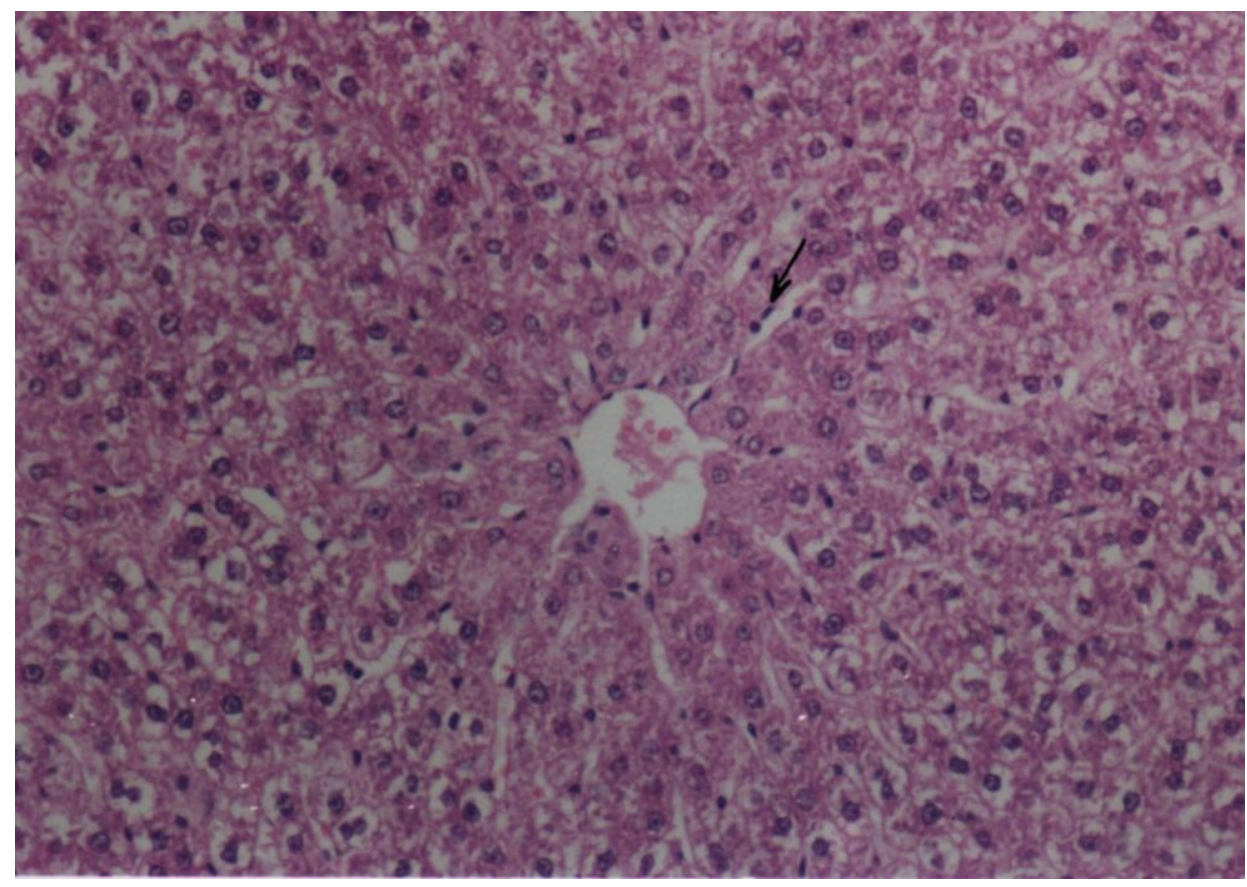

Fig.6:- Liver of a rat exposed to the fractionated dose of gamma irradiation showing Kupffer cell activation (arrow) and mild hydropic degeneration in hepatocytes. Cortical hepatocytes appeared more affected than central ones. (Hx and E X 200). 


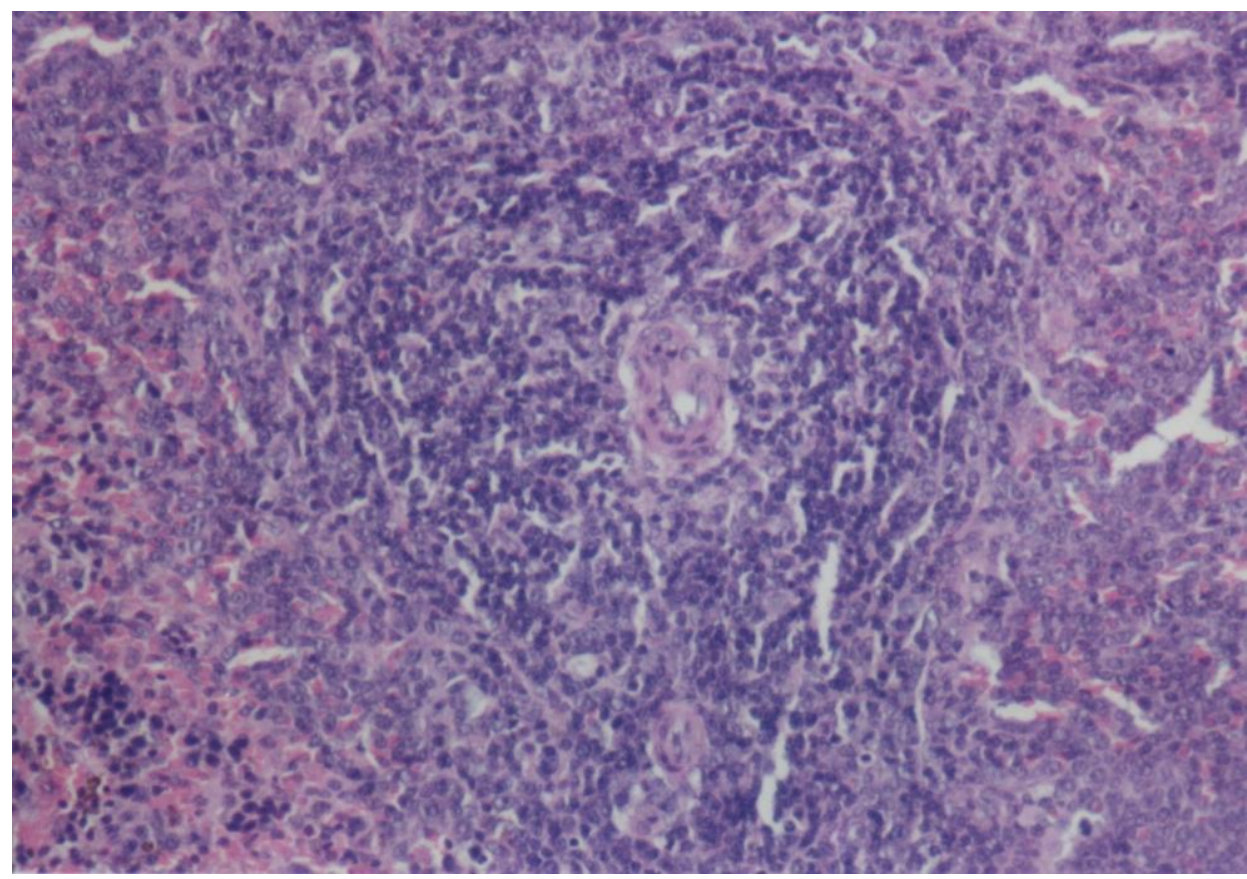

Fig.7:- Spleen of a control non irradiated rat showing the normal histological structure of the white and red pulp. (Hx and E X 200).

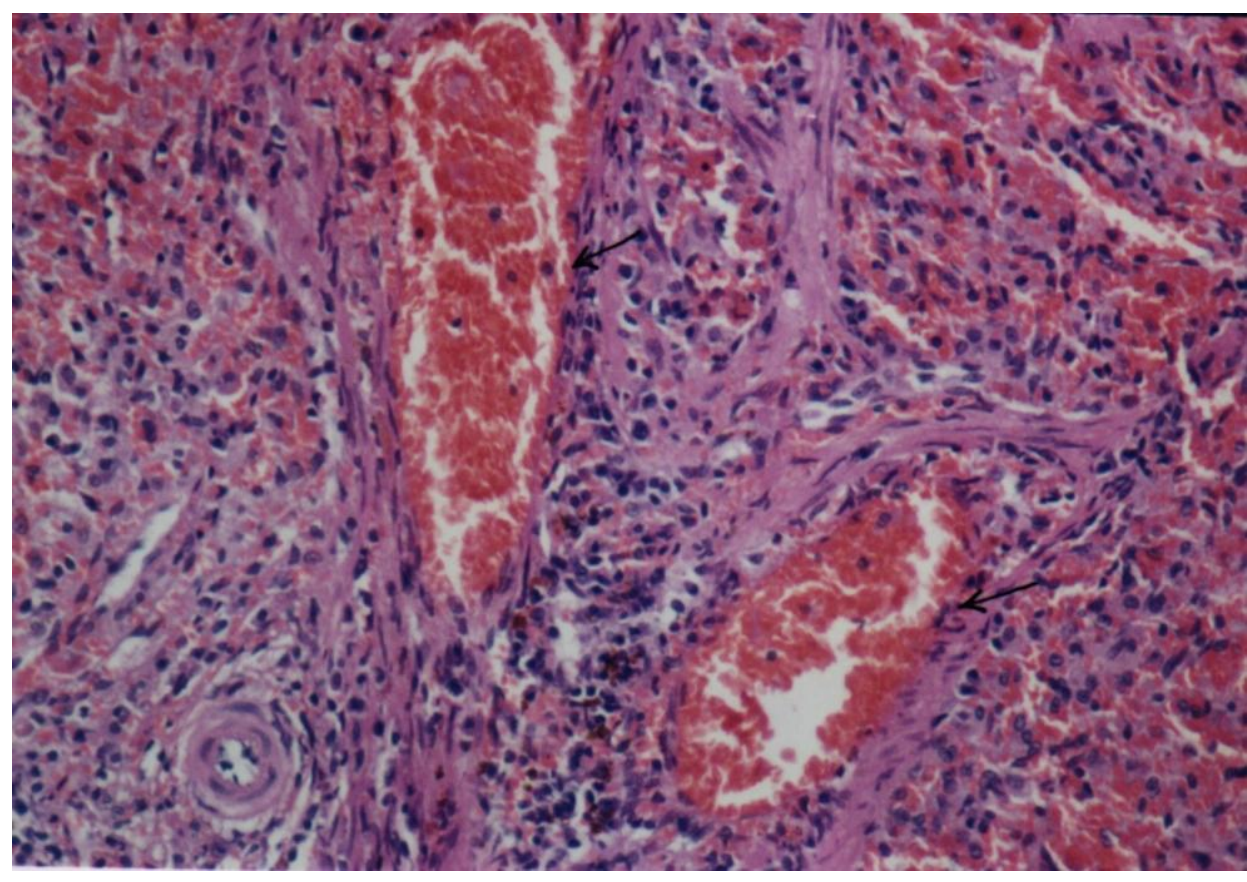

Fig.8:- Spleen of a rat exposed to the single dose of gamma irradiation (5Gy) showing marked congestion of splenic blood vessels with prominent internal haemorrhage (arrows). (Hx and E X 200). 


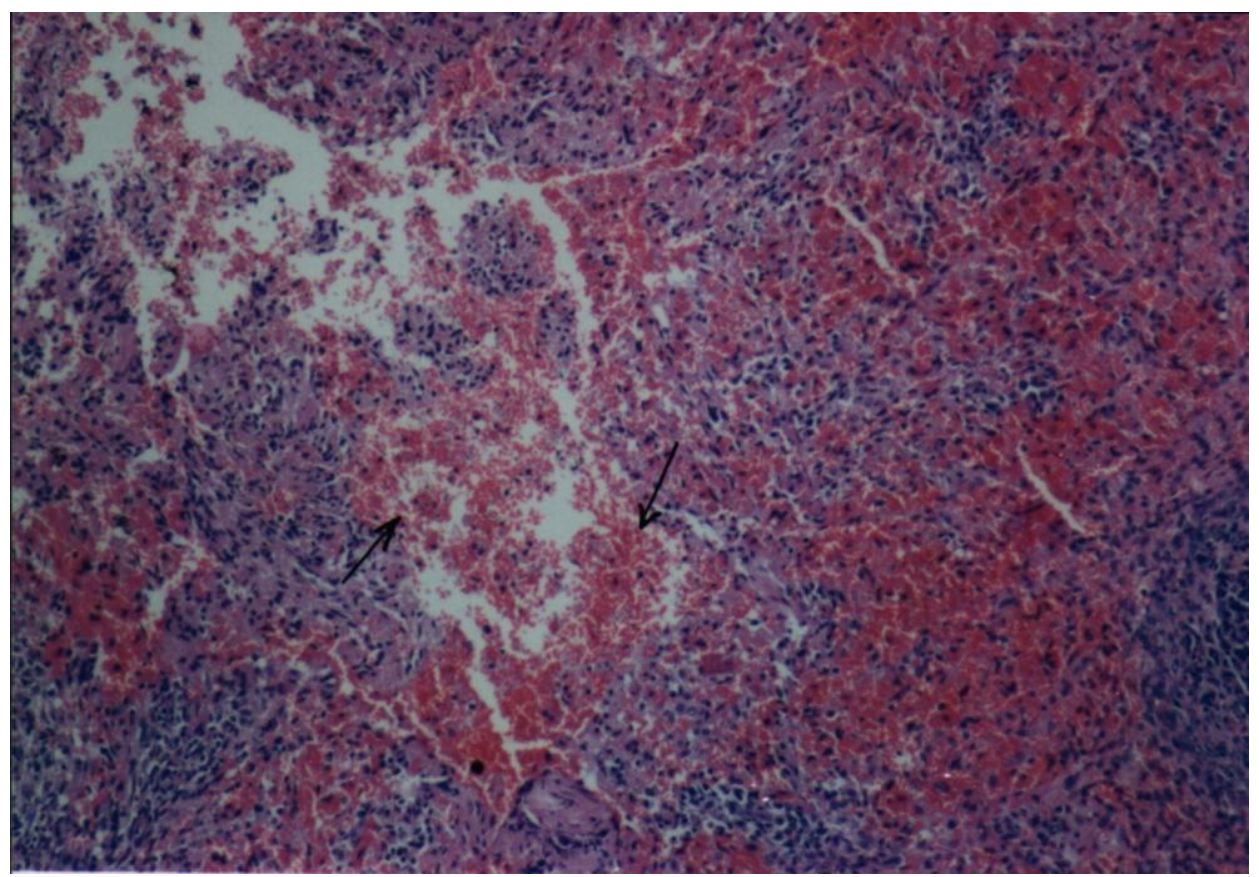

Fig.9:- Spleen of a rat exposed to the single dose of gamma irradiation (5Gy) showing massive splenic haemorrhage, ill defined pulps, since large areas are destructed (arrows). The spleen lost its normal architecture. (Hx and E X 100).

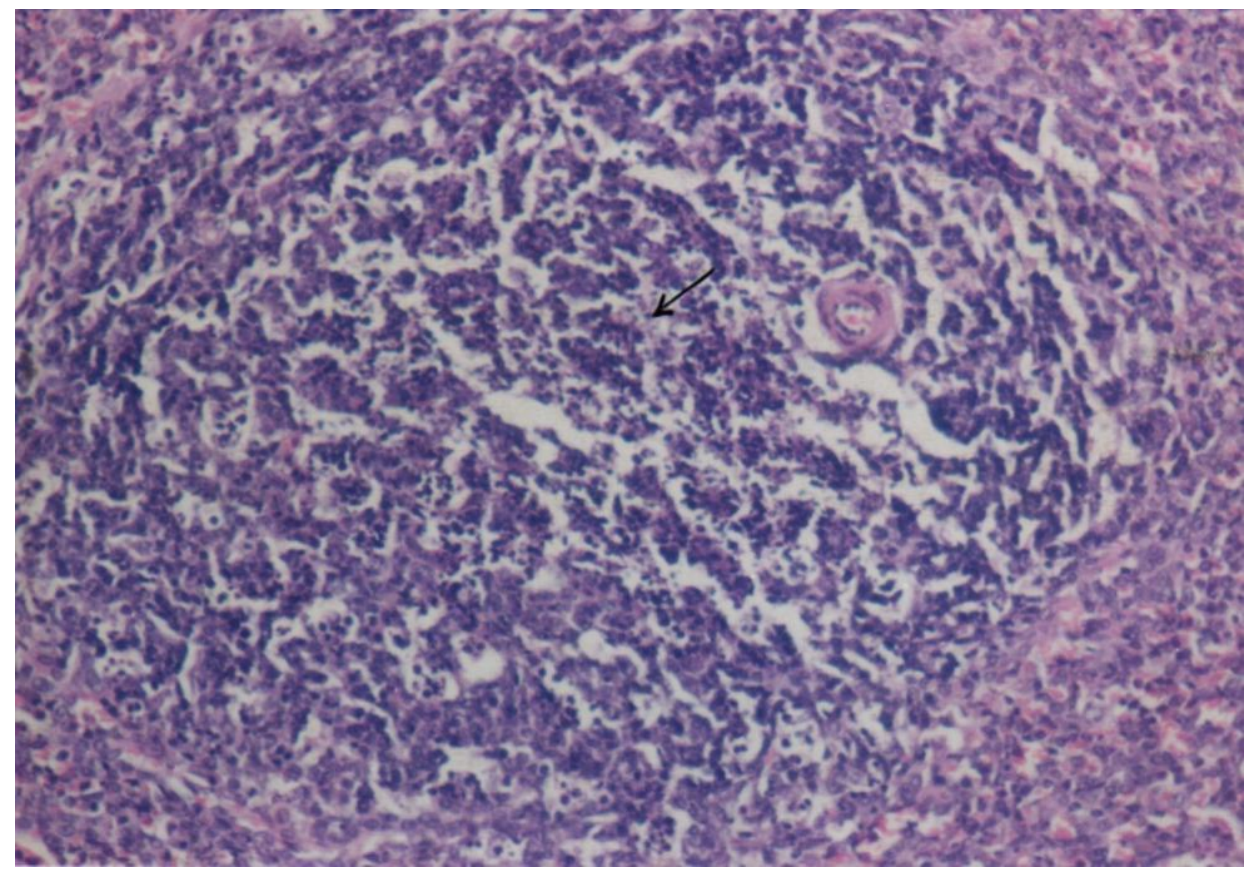

Fig.10:- Spleen of a rat exposed to the fractionated dose of gamma irradiation showing slight lymphocytic necrosis with enlarged white pulp (arrow). (Hx and E X 200). 


\section{Nabila A. R. Abdel Motaal \& Azza Abdel Maguid}

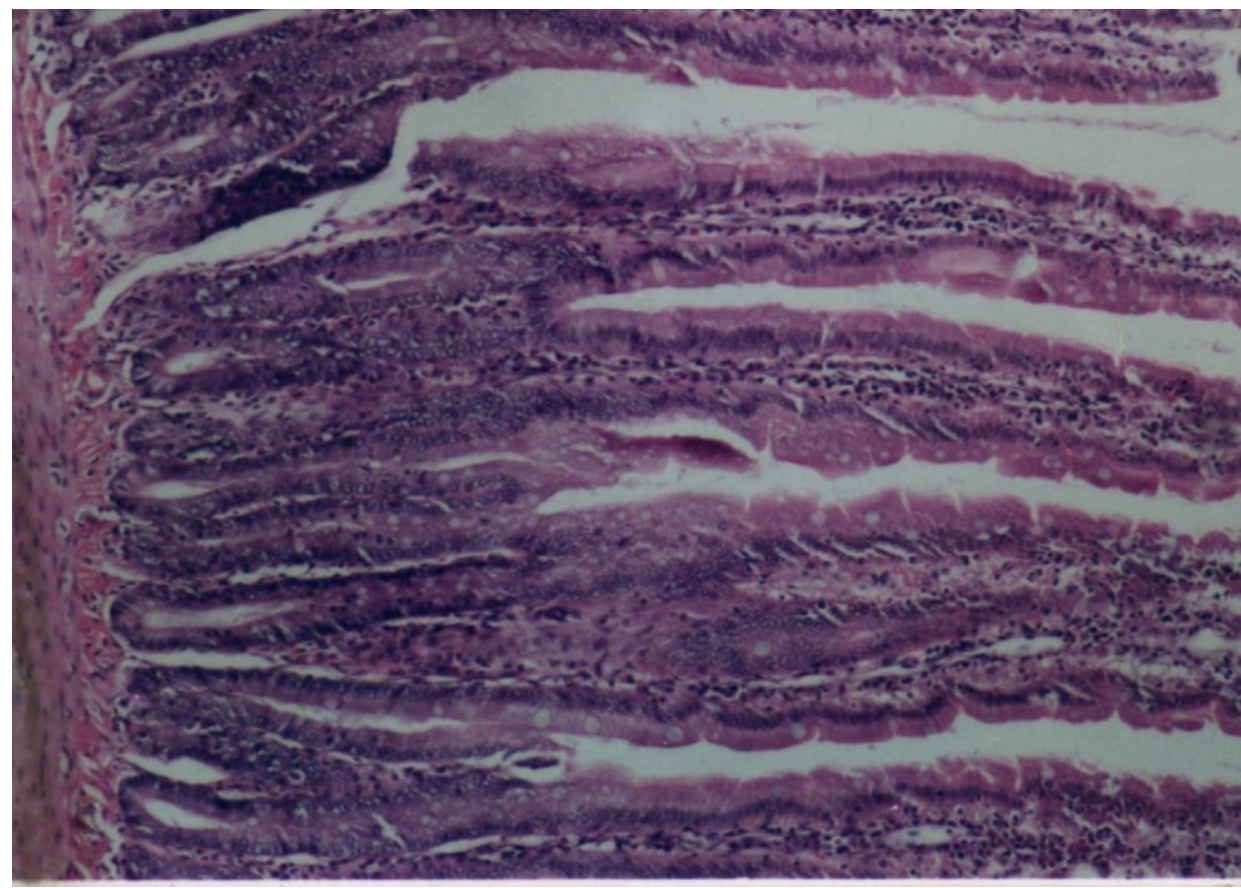

Fig.11:- Intestine of control, non irradiated rat showing normal well developed intestinal villi. (Hx and E X 100).

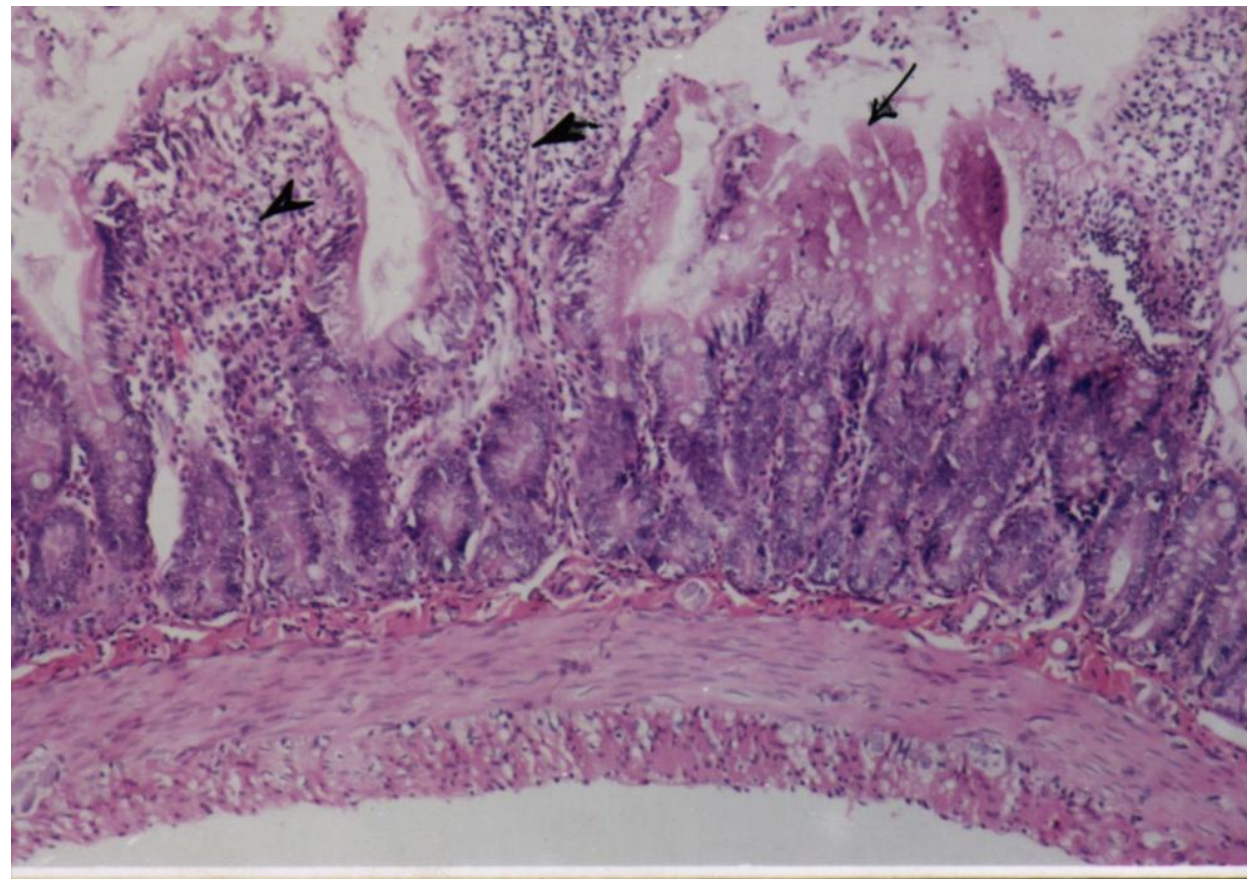

Fig.12:- Intestine of a rat exposed to the single dose of gamma irradiation (5Gy) showing focal exfoliation of intestinal villar epithelium (arrow), activation of intestinal glands and mononuclear infiltration in the lamina propria (arrow head) Villi appeared short and thick with ruptured columnar cells (v). (Hx and E X 100). 


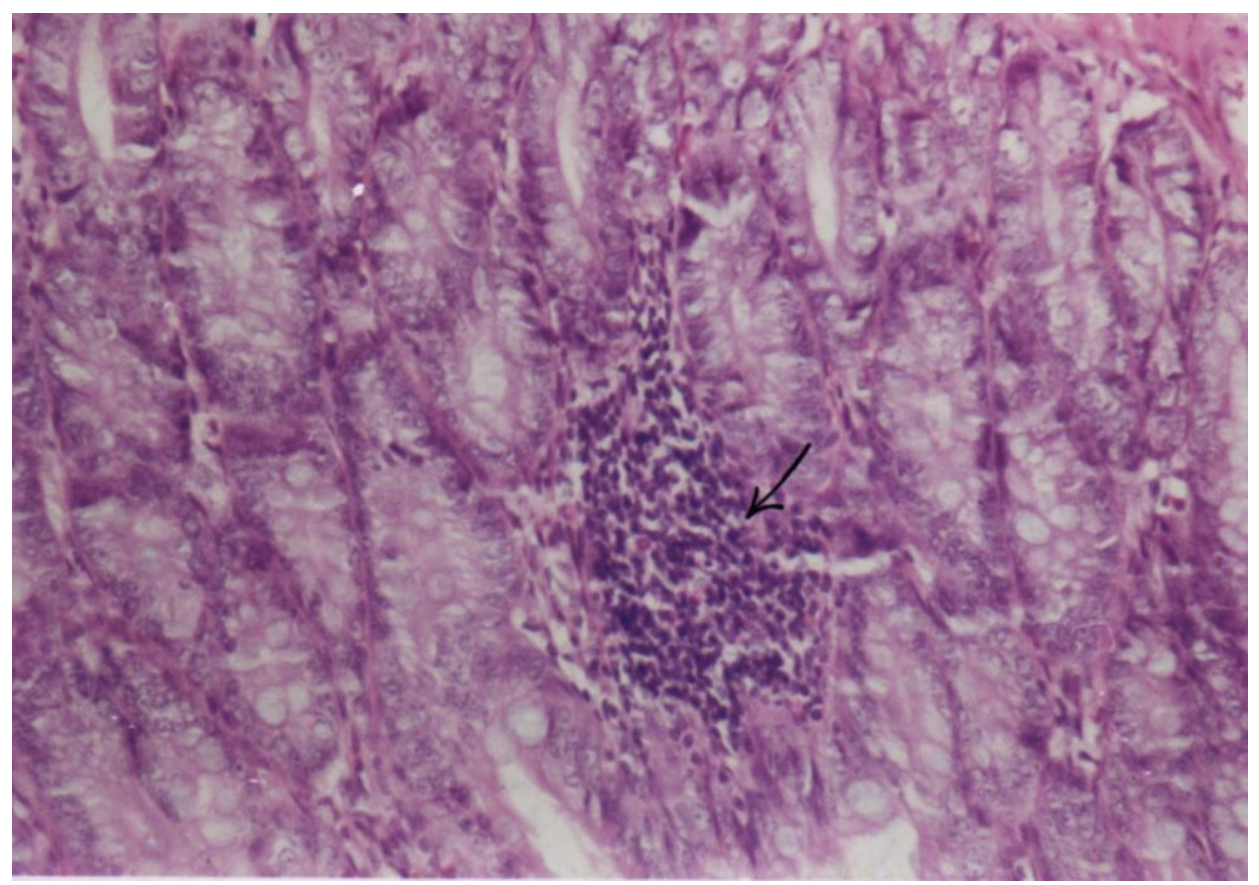

Fig.13:- Intestine of a rat exposed to the single dose of gamma irradiation (5Gy) showing activation of mucous secreting glands and a large mass of mononuclear cells infiltration. Villi containing the debris of their cytoplasm and nuclei (arrow). (Hx and E X 200).

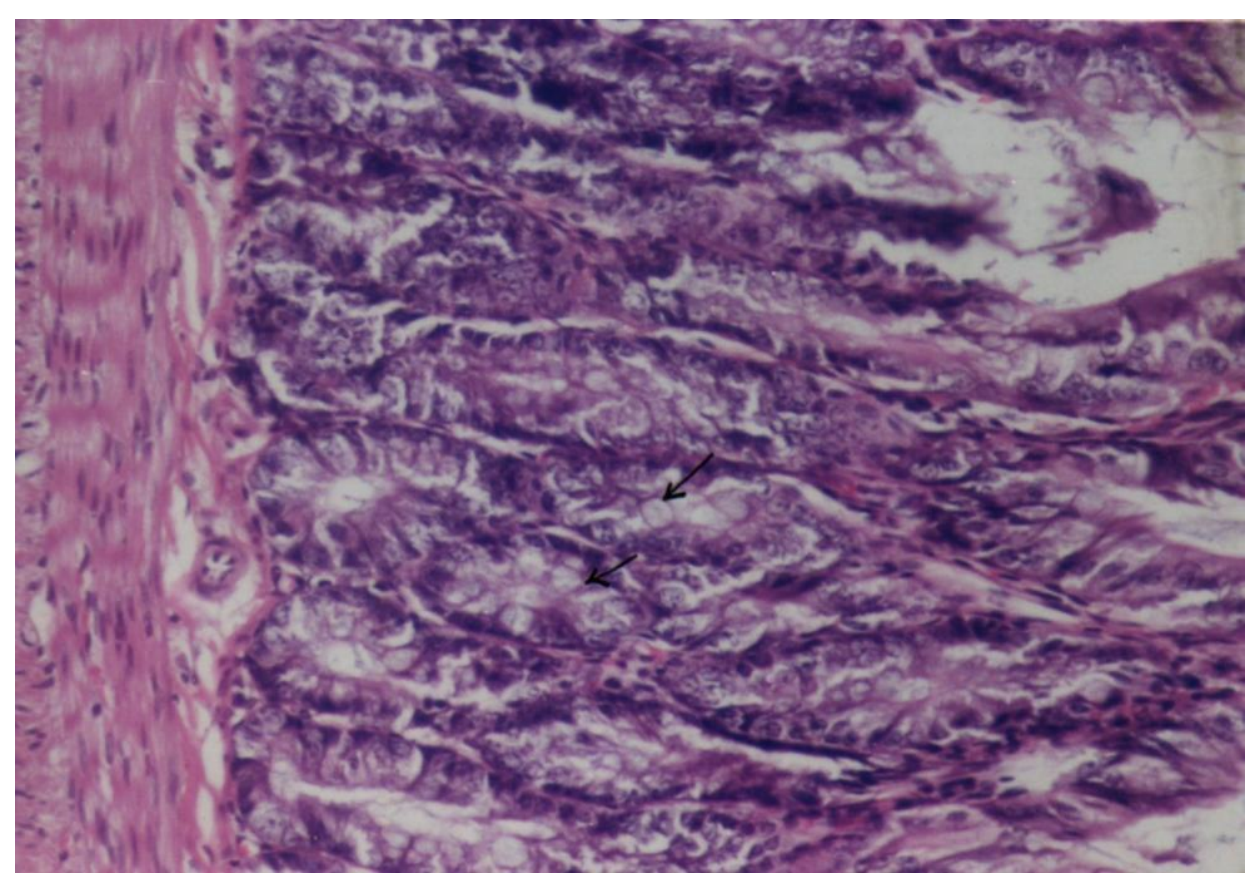

Fig.14:- Intestine of a rat exposed to the fractionated dose of gamma irradiation showing activation of mucous secreting glands (arrows) with enlarged villi and few villi are ruptured (arrow head). (Hx and E X 200). 


\section{Discussion}

All cells are susceptible to damage by ionizing radiation (El Shakankery, 1989). DNA, lipids in cell membrane and proteins are the most important targets in living cells (Kumar et al., 2003).

Results of the present study revealed that whole body gamma irradiation (single dose) at 5Gy caused serious histopathological alterations in the liver, spleen and intestine of rats, and this was reported by other workers (Moussa et al., 1984, Roushdy et al.,1988, El-Gharib et al.,1999 and Abd El Maguid et al.,2004). Whole body gamma irradiation at fractionated sub lethal dose level of $1 \mathrm{~Gy}$ up to a cumulative dose of 5Gy resulted in amelioration and reduction of the severity of the histological disorders in the liver, spleen and small intestine induced by single dose gamma irradiation (5Gy). These results are in agreement with the finding of Abd El Maguid (1983). After irradiation most cells may undergo repair if sufficient time was permitted between two successive doses. The repair may be very much slower in late responding tissues. The extent of repair varies widely among different cells and tissues (Sutherland, 1992).

The liver tissue of rat exposed to single shot gamma irradiation (5Gy) showed congestion of the central vein, hepatic sinusoids and hepatoportal blood vessels. The endothelial lining of the hepatic portal vein was detached and irregular. Also portal haemorrhages and portal infiltration with mononuclear cells were seen. Moreover hepatocytes appeared vacuolated and the nuclei were highly affected: Some of them were irregular, others were atrophied while some of them appeared surrounded by large clear area. Hepatic necrosis with pyknotic nuclei and massive hepatic haemorrhage were detected. Also disturbed bile canaliculi could be seen. Similar results were reported by other workers. Abd El Maguid et al. (2004), reported that exposure of rats to 6Gy gamma irradiation induced marked histopathological and histochemical alterations in the liver. Said et al, (2005) stated that radiation caused rupture of hepatic cells membrane, vacuolated cytoplasm, pyknotic nuclei, dilated sinusoids and fibrotic changes in and around hepatic veins. This could be explained on the basis that exposure to radiation increases mitotic delay (Grosch and Hopwood, 1979).

The spleen showed histopathological changes as a result of exposure of rats to the single dose gamma irradiation (5Gy) manifested by marked dilatation and congestion of splenic blood vessels, lymphocytic necrosis and depletion as well as massive splenic haemorrhages accompanied with deposition of golden brown haemosiderin pigments. These findings are supported by Abd-El-Rahman and Saad El-Din (1996) who reported that irradiation caused distortion of splenic architecture together with congestion of blood sinusoids and lymphocytic depopulation from the white pulp.

Histopathological examination of the small intestine after irradiation with 5Gy (single dose) showed focal denuation and exfoliation of intestinal villi epithelium, activation of mucous secreting intestinal glands as well as mononuclear cells infiltration in the lamina propria. Similar results have been obtained by other workers (Sanad, 1979, Moussa, 1987 and Ramadan et al.; 1998). Rezk (2005) reported that whole body gamma irradiation of rats with a single dose produced histological damage in the small intestine manifested by edema and congestion of mucosa, atrophy and illdefined shape of villi and crypts and loss of villi, with epithelial sloughing. The villi appeared short and thick with ruptured columnar cells.

The histological damage might result from an increase in the process of lipid peroxidation and a decrease in the activity of antioxidant enzymes of the body with the consequent damage of cellular biomembranes (El Habit et al., 2000 and Saada et al., 2001).

Furthermore this study has clearly shown that fractionation of doses of radiation seems to be more safe when 
planning radiotherapy for cancer patients, in order to minimize the serious damaging effects of radiation on the different organs.

\section{References}

1. Abd El Maguid, A. (1983): Microscopic studies on some haemopoietic organs of albino rat after repeated irradiation. M.Sc. Thesis, Faculty of medicine, AlAzhar University, Cairo. Egypt.

1. Abd El Maguid, A.; El Gharib, R. and Ahmed, K.A. (2004): Possible protection role of melatonin against radiation induced histopathological and histochemical changes in the liver of male albino rats. J. Egypt. Ger. Soc. Zool. 45C: 1-13.

2. Abd-El-Rahman, N. and Saad El-Din, A.A. (1996): Effect of continuous gamma irradiation on highly proliferated cells. Egypt. J. Biomed. Engng. 12:21-30.

3. El-Gharib, R. F.; Fahmy, N.; Abd El Maguid, A. and Saber, F. H. (1999): Studies on radiation injury and recovery on liver using silymarin. Egypt. J. Histol., 22(1\&2): 111-124.

4. El Habit, O.M., Saada, H.N., Azab, Kh. Sh., Abdel Rahman, M. and El-Malah, D. F. (2000): The modifying effect of beta carotene on gamma radiationinduced elevation of oxidative reactions and geno-toxicity in male rats. J. Mutation. Res., 466:179.

5. El Shakankery, A.A.W.(1989): Studies of the bone marrow reserve power in cancer patients receiving chemo or radiotherapy. MD thesis, Faculty of medicine, Cairo University.

6. Fowler, J. F. (1994): Fractionation in radiotherapy. Semin Radiat. Oncol. 2: 1-7.

7. Grosch, D. S. and Hopwood, L.E. (1979): Biological effects of radiation. $2^{\text {nd }}$ Ed. Academic Press, New York, San Francisco, London.

8. Halliwell, B. and Gutteridge, J.M. (1989): "Free Radicals in biology and medicine". $2^{\text {nd }}$ ed.,Oxford,Clarendon Press.
9. Hassan, S. H.M. and Osman,S.A.A. (1996): Restoration of impaired carbohydrate metabolism in irradiated albino rats through treatment with vitamin B complex and/or folic acid. Egypt. J. Rad. Sci. \& Applic., 9(1): 43.

10. Jirtle, R.L., Anscher, M.S. and Alati, T. (1990): Radiation sensitivity of the liver. In " Advances in Radiation Biology" Vol. 14. Academic Press, San Diego.

11. Kissan, J.M. and Anderson, W.A.D. (1985): Radiation injury. In Anderson's pathology, Eigth ed. The C.V. Mosby Company, St. Louis Toronto. 242.

12. Kumar, V.; Cotran, R.S. and Robbins,S.L. (2003):

Environmental Diseases. In Robbins Basic Pathology, $7^{\text {th }}$ ed. Saunders. Philadelphia London Toronto. p. 288.

13. Moussa, J. A.; Roushdy, H. M.; Riad, N. A.; El-Zahaby, E. A. S. and sanad, S. M. K. (1984): Histochemical studies on neurons of $\mathrm{x}$-irradiated rats. Egypt. J. Histo., 7(2): 229-237.

14. Moussa, J. A. (1987): The role of immune system in the recovery process after irradiation injury. Ph.D. Thesis, Faculty of medicine, Al azhar university, Egypt.

15. Ramadan, L.A.; Ghazaly, M. A.; Moussa, L.A.; Saleh, S.; ElDenshary, E.S. and Roushdy, $H$. (1997-1998): Radioprotective effect of thiola on radiation induced functional and structural changes in rat intestine. Egypt. J. Rad. Sci., Applic. 10-11: 39-58.

16. Rezk, R.G. (2005): Modulatory role of Aloe vera on Gamma Irradiation-Induced Histological changes in different tissues of rats. Egypt. J. Rad. Sci., Applic. 18 (1): 97-115.

17. Roushdy, H. M.; Mausom, K. and Abugalal, H. (1988): Histopathological studies of the liver of pregnant rats subjected to w.b. gamma irradiation. Egypt. J. Radiation Science \& Appl., 2:19.

18. Saada, H. N., Azab, Kh. Sh. And Zahran, A. M. (2001): Postirradiation effect of branchovason, O. M. $85 \mathrm{~B} \mathrm{~V}$, and its 
relationship to anti-oxidant activities. J. Pharmazie, 56: 239.

19.Said, U.Z., Rezk, R.G. and Saada, H.N. (2005): Role of calcium Pantothenate in recovery of radiation induced injury to mammalian organs. . Egypt. J. Rad. Sci.,

20. Sanad, S. M. (1979): Studies on the response of certain mammalian organs to irradiation treatments. M.Sc. Thesis, Faculty of Science, Zagazig University, Egypt.

21. Sutherland, R.M. (1992): Chemical modification: Radiation and cytotoxic drug. Int. J. Radiat. Oncol. Biol. Phys. 8: 323-325.

\section{التأثير الناتج عن التعرض المتكرر و المرة الواحدة لآشعة جاما على بعض أعضاء

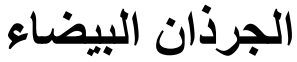

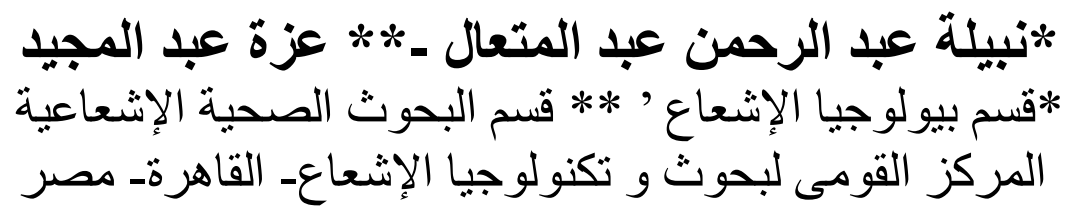

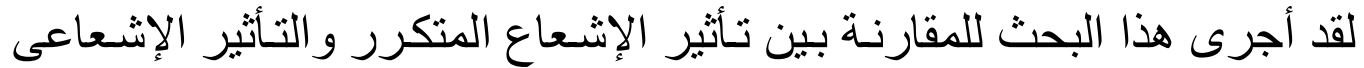
للمرة الواحدة على خلايا الكبد و الطحال و الأمعاء الدقيقة.

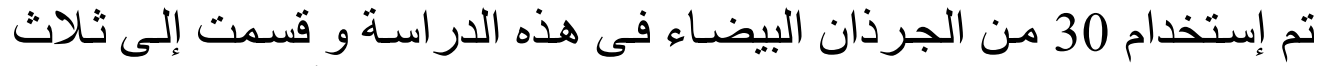

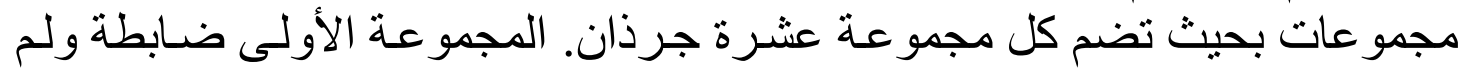

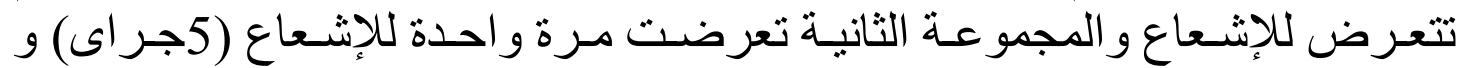

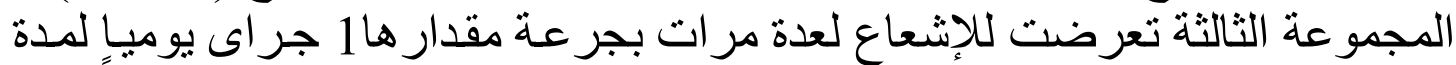
خمسة أيام منتالية.

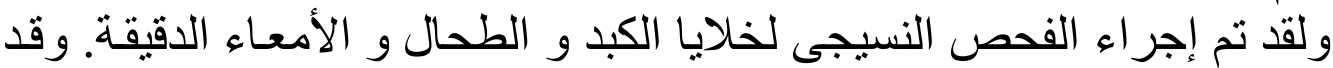

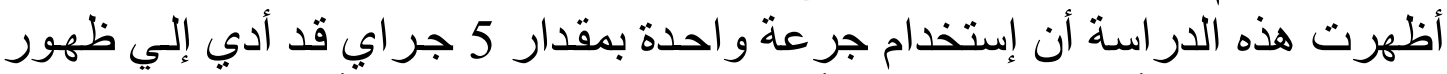

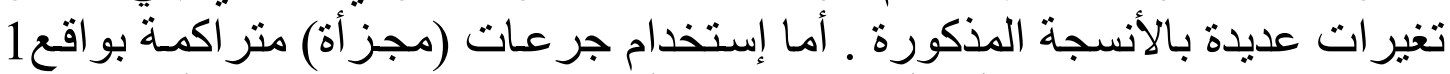

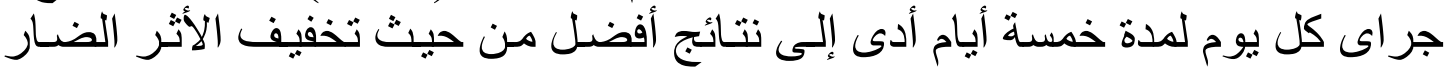

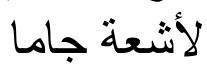

ومن هذا المنطلق ننصح بأن يكون علاج مرضى السرطان بجرعات مجز أة أحسن بكثير من إستخدام جر عات كبيرة مرة ونان واحدة. 